\section{Cureus}

\title{
Development of a Sustainable Simulator and Simulation Program for Laparoscopic Skills Training in Haiti
}

Emile Damas ${ }^{1}$, Chesnel Norcéide ${ }^{2}$, Yvel Zephyr ${ }^{3}$, Kerry-Lynn Williams ${ }^{4}$, Tia S. Renouf MD ${ }^{5}$ , Adam Dubrowski 6

1. Surgery Department, Justinien University Hospital 2. Paediatrics, Justinian University Hospital 3. Department of OBGYN, Director of Training and Research, Justinien University Hospital 4. Faculty of Medicine, Memorial University of Newfoundland, St. John's, CAN 5. Emergency Medicine, Memorial University of Newfoundland/Tairawhiti Hospital, Gisborne, NZL 6. Emergency Medicine, Memorial University of Newfoundland, St. John's, CAN

$\square$ Corresponding author: Adam Dubrowski, adam.dubrowski@gmail.com Disclosures can be found in Additional Information at the end of the article

\section{Abstract}

Laparoscopic surgery has been shown to have many favorable effects on surgical outcomes and postoperative recovery times. However, the cost of currently available training programs, such as the Fundamentals of Laparoscopic Surgery (FLS), limits their adoption in developing countries. To address this cost constraint, educators at the Justinian University Hospital (JUH) in Northern Haiti used local materials to build their own laparoscopic skills box trainer. This trainer is used to teach all surgical and OB/GYN residents in their laparoscopic skills program. The progressive curriculum consists of seven modules, three of which are for all trainees and four of which are specifically for surgery and OB/GYN (2). The seven modules are arranged in the order of difficulty; they start with basic maneuvers and progress to complex skills. This report describes both the preparation of the seven models and evaluation of the skills that are learned. This approach may facilitate global access to feasible, progressive, and sustainable laparoscopic training.

Categories: Medical Education, Medical Simulation

Keywords: laparoscopic, haiti

\section{Introduction}

Laparoscopic surgery has many advantages for patient care, chiefly, minimal trauma to tissues and faster postoperative recovery times. It is a common technique in developed countries. However, it been only minimally adopted in developing countries, like Haiti, despite the availability of telesimulation for training laparoscopic surgery teachers [1-8]. Fundamentals of Laparoscopic Surgery (FLS) is, for example, one well-established and validated example of telesimulation that was successfully implemented in Botswana. Using SKYPE, an FLS-certified trainer in Canada was able to supervise FLS training sessions in that country. Though in many ways a feasible solution, access to equipment was problematic. That is, the trainees in Botswana were required to use FLS-certified trainers and exercises; these are prohibitively expensive in some contexts.

The Justinian University Hospital (JUH) is Northern Haiti's primary teaching institution. It trains its residents in laparoscopic surgery at Milot and Pignon, two nearby hospitals that perform the technique. It was determined that simulation-based education at the JUH would 
help to prepare residents to further this laparoscopic work in Milot and Pignon.

This report describes a feasible approach to laparoscopic skills training, developed at JUH for all their surgical and $\mathrm{OB} / \mathrm{GYN}$ residents. Educators there used local materials to build a box trainer, like the FLS trainer, in order to provide accessible education for trainers and students working in that resource-poor region. The program uses the progressive simulation training approach described by Cristancho, et al. [9-10], along with validated assessment methods. With progressive simulation, a given complex procedure is deconstructed into its subcomponents (skills), which are then further deconstructed to their subcomponents (tasks). This is a hierarchical training approach; only after the learner becomes proficient at skills can he or she begin to practice tasks. They can practice the entire procedure once they have developed task proficiency. Learning objectives are written for these skills, tasks, and procedures; they consequently inform the types of simulation used both for practice and assessment.

\section{Technical Report}

\section{Box trainer}

Dr. Damas Emile from the JUH developed the laparoscopic box trainer (Figure 1). The outer shell is constructed from cardboard and is covered with plastic. There are five ports on the top surface and two laterally. The interior of the box trainer is illuminated with a standard $15 \mathrm{~W}$ lamp. A Logitech HD Webcam C270 web camera (Logitech, Newark, CA), placed at the back of the trainer and connected to a laptop computer, serves as a display. Alternatively, for classroom-type viewing, the computer can be connected to a different display device, such as an LCD projector or screen. 


\section{Cureus}

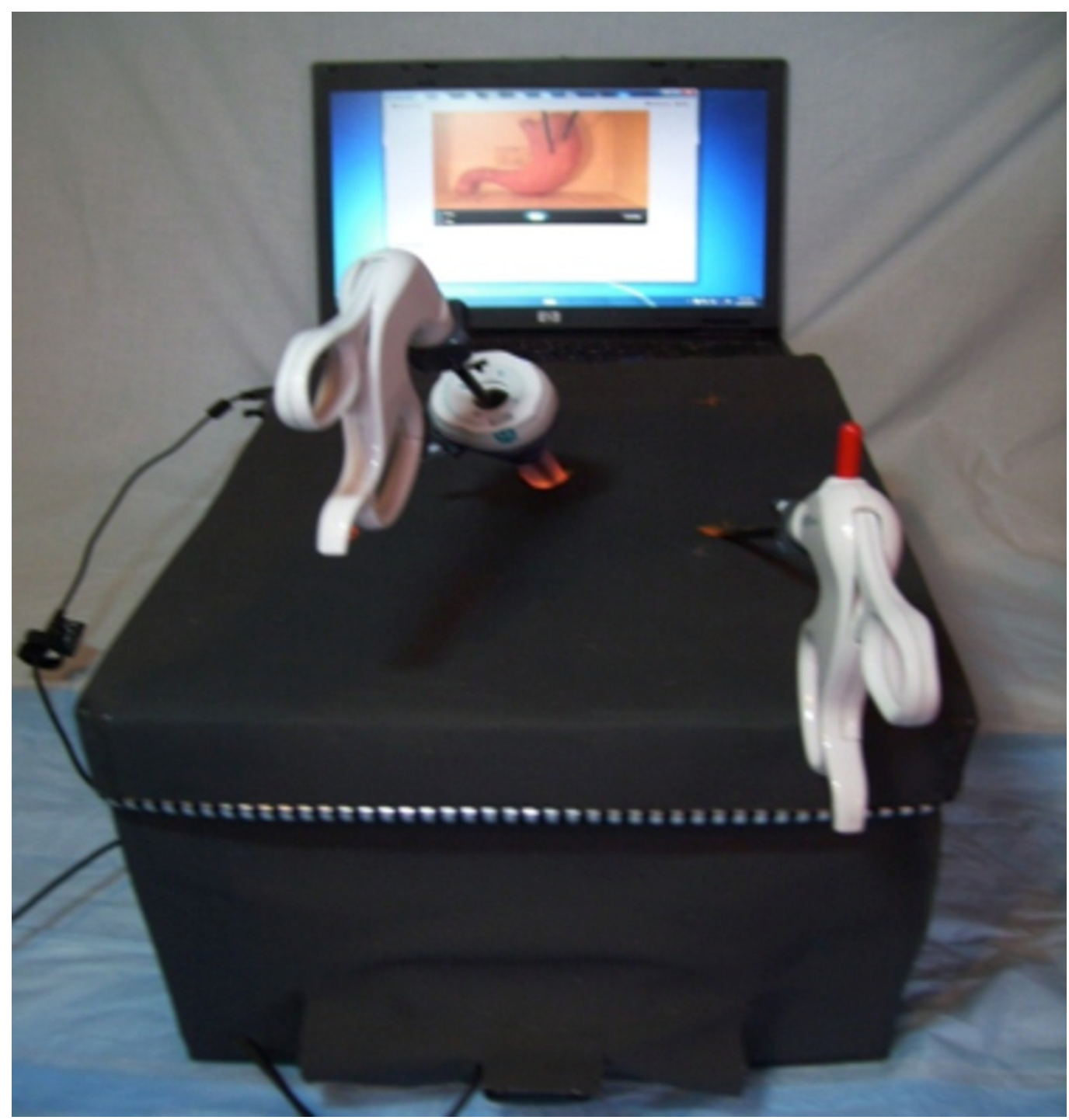

FIGURE 1: Laparoscopic box trainer.

\section{Curriculum}

The simulation-based laparoscopic skills curriculum for senior surgical and OB/GYN residents is based on progressive training. It consists of seven modules, three of which are shared amongst all trainees; the other four are specifically for surgery (two) and OB/GYN (two). The seven modules are arranged in order of difficulty, starting with basic maneuvers and progressing to more specific, complex skills (Table 1). 


\section{Cureus}

\begin{tabular}{|c|c|c|c|}
\hline $\begin{array}{l}\text { Training } \\
\text { Level }\end{array}$ & Training Module & Objectives & Assessment \\
\hline $\begin{array}{l}\text { Basic } \\
\text { skills }\end{array}$ & $\begin{array}{l}\text { 1. Peg transfer } \\
\text { 2. Cutting } \\
\text { 3. Suturing and } \\
\text { foam tying on a } \\
\text { foam pad }\end{array}$ & $\begin{array}{l}\text { - Learn basic maneuvers } \\
\text { - Hand-eye coordination } \\
\text { - Working in 3D space using 2D displays }\end{array}$ & $\begin{array}{l}\text { - Time } \\
\text { - Precision } \\
\text { - Global } \\
\text { Rating } \\
\text { Scales }\end{array}$ \\
\hline $\begin{array}{l}\text { Complex } \\
\text { skills }\end{array}$ & $\begin{array}{l}\text { 4. Cholecystectomy } \\
\text { 5. Pyloroplasty } \\
\text { 6. Ectopic } \\
\text { pregnancy } \\
\text { 7. Ovarian } \\
\text { cystectomy }\end{array}$ & $\begin{array}{l}\text { For each of the skills, the objective is to learn all } \\
\text { necessary skills and optimize the flow of } \\
\text { performance (become proficient). }\end{array}$ & $\begin{array}{l}\text { - Global } \\
\text { Rating } \\
\text { Scales } \\
\text { - Appropriate } \\
\text { task- } \\
\text { specific } \\
\text { checklists }\end{array}$ \\
\hline
\end{tabular}

TABLE 1: Summarized Proposed Progressive Laparoscopic Skills Curriculum

Basic skills, like hand-eye coordination and manipulating three-dimensional (3D) space using two-dimensional (2D) displays, are taught in Modules 1-3. This is accomplished by practicing general manual skills, such as peg transfer, cutting, suturing, and knot tying. Modules 4-7 progress to more complex procedures. Surgical learners move to a cholecystectomy module (Module 4), and pyloroplasty (Module 5), whereas OB/GYN learners progress to a simulated ectopic pregnancy module (Module 6) and a simulated ovarian cystectomy (Module 7).

Learning objectives and metrics are provided for each simulation module. For the basic skills (Modules 1-3), the metrics are either time or precision; for the complex procedures (Modules 47), a Global Rating Scale (GRS) (Table 2: modified from Reznick, et al.) [11-13] and task-specific checklists are used (refer to sections below for sample of checklists for each module). 


\section{Cureus}

\section{Performance}

Characteristic

\section{Rating}

Depth

perception

Constantly overshoots target, wide swings, slow to correct

Bimanual dexterity

$$
1
$$

Uses only one hand, ignores nondominant hand, poor coordination between hands

Efficiency $\quad 1$

Uncertain, inefficient efforts, many tentative movements, constantly changing focus or persisting without progress

Tissue handling 1

Frequent use of unnecessary force, tears tissues, injures adjacent structures, poor grasper control, grasper frequently slips

\section{Autonomy 1}

Unable to complete entire task, even with verbal guidance

Instrument handling
Some overshooting or missing of target, but quick to correct

23

Uses both hands but does not optimize interaction between hands

Efficient progress but some unnecessary movements

23

Handles tissue reasonably well, minor trauma to adjacent tissue (i.e. occasional unnecessary bleeding or slipping of the grasper)

23

Able to complete task safely with moderate guidance

23

Competent use of instruments but occasionally appeared stiff or awkward
Accurately directs instruments in the correct plane to target

45

Expertly uses both hands in a complementary manner to provide optimal exposure

45

Confident, efficient, and safe conduct, maintains focus on task until it is better performed via an alternate approach

45

Handles tissue well, applies appropriate traction, negligible injury to adjacent structures

45

Able to complete task independently without prompting

45

Fluid moves with instruments and no awkwardness

\section{TABLE 2: Objective Structured Assessment of Technical Skills}

"1" indicates worst possible score and "5" indicates best possible score 


\section{Cureus}

\section{Module 1: Peg transfer}

The residents' learning objective here is to develop laparoscopic dexterity. They will also learn how to work within 3D space using 2D displays by manipulating the laparoscopic graspers, and by practicing independently until they reach a predefined level of proficiency [14-15]. Performance, as it relates to proficiency, is measured by timing (time spent) and precision (number of pegs dropped) (Figure 2).

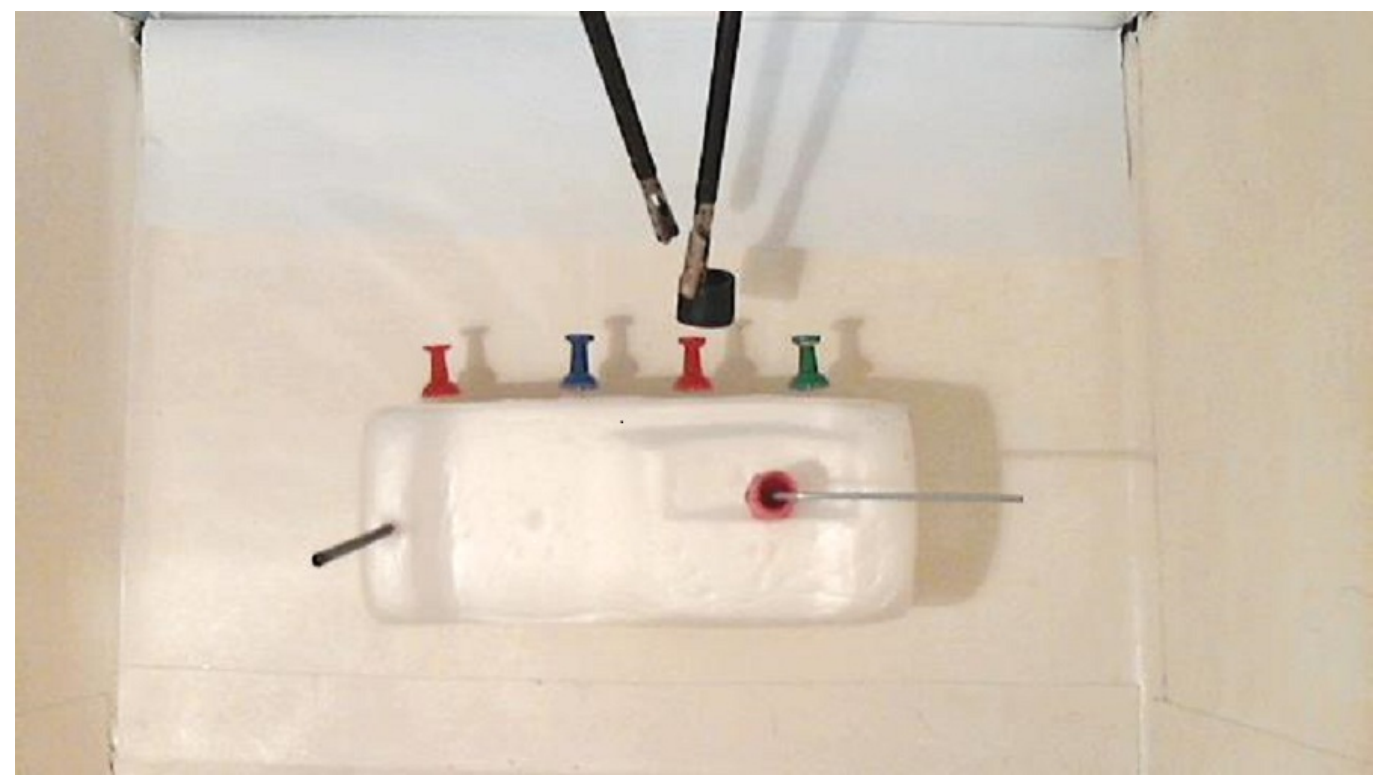

FIGURE 2: Laparoscopic peg transfer.

\section{Module 2: Cutting}

A circular pattern is cut along a $1 \mathrm{~mm}$-wide line (Figure 3). The residents' learning objectives here are again to develop laparoscopic dexterity and to work within a 3D space using 2D displays while using laparoscopic scissors. Residents practice independently until they reach the predefined proficiency as in Module 1. 


\section{Cureus}

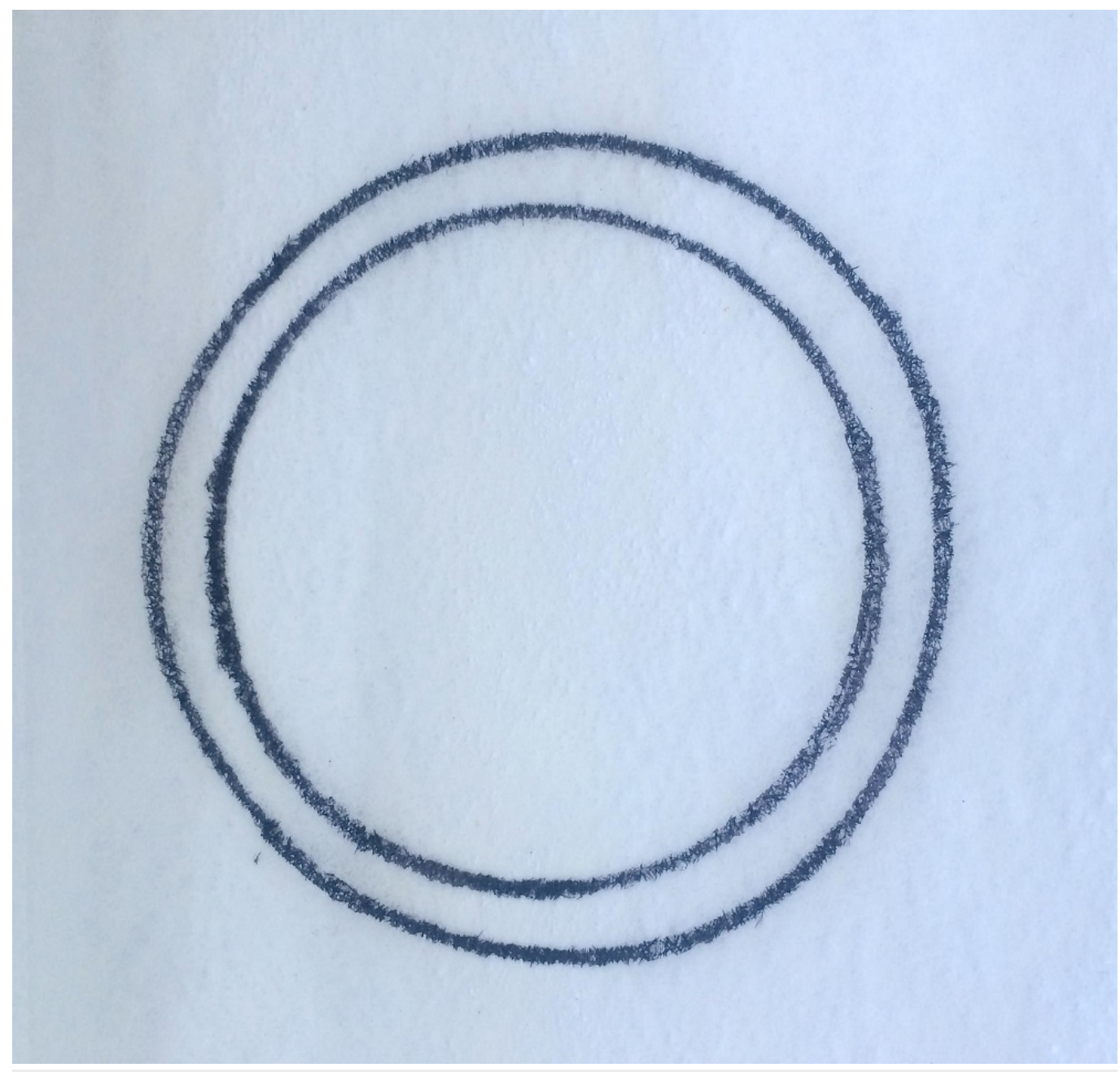

FIGURE 3: Laparoscopic cutting.

\section{Module 3: Suturing and knot tying on a foam pad}

Learning objectives for this module are the same as above (to develop laparoscopic dexterity and to work within 3D space using 2D displays) as well as to acquire basic laparoscopic suturing and knot tying skills. This is accomplished by placing a strip of foam $(20 \mathrm{~cm} \times 5 \mathrm{~cm})$ in the trainer (Figure 4). The goal for residents is to make a tube out of the rectangular foam by suturing the two edges of the foam together. 


\section{Cureus}

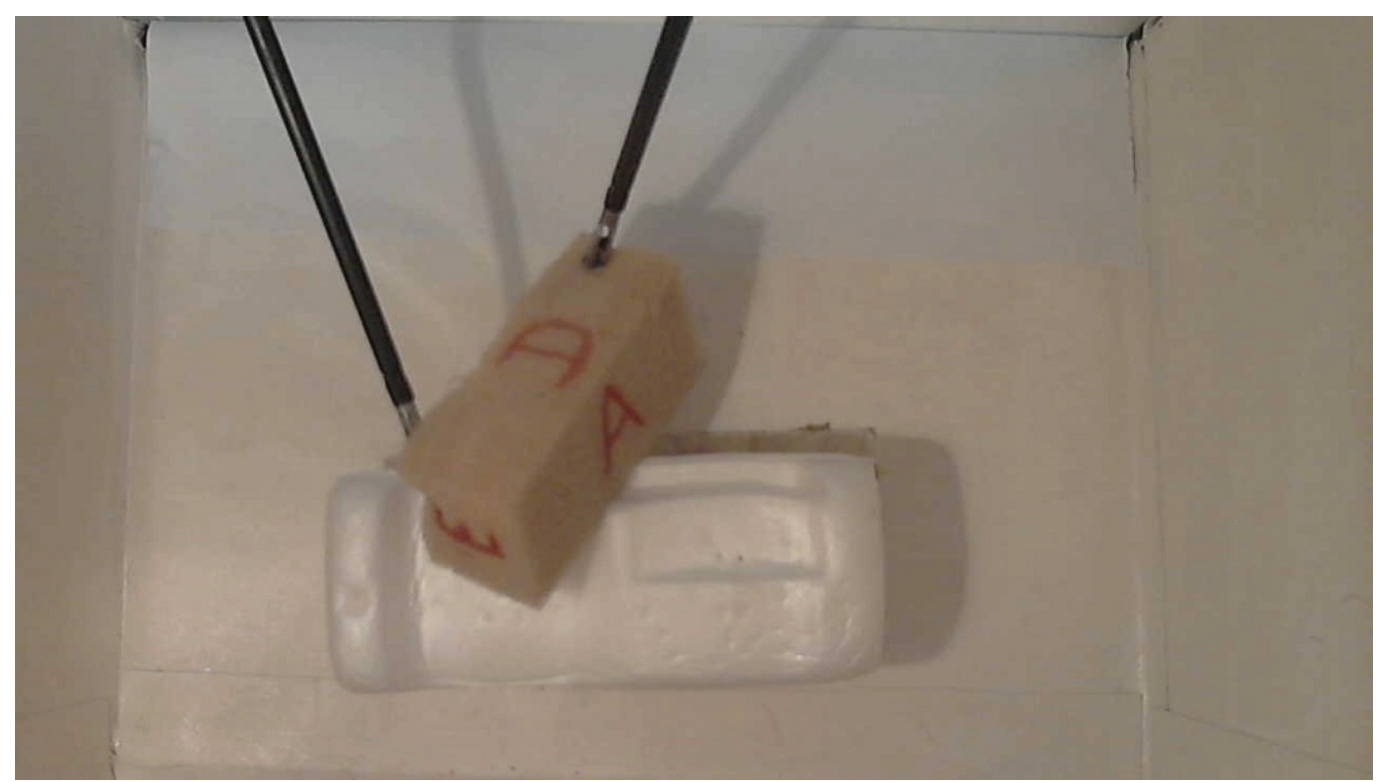

FIGURE 4: Suturing and knot tying on a foam pad.

An experienced trainer supervises the practice sessions during this module. The trainer can provide both formative and summative feedback based on the GRS (Table 2) and skill-specific checklist (Table 3) adapted from Reznick, et al. [11, 16]. 


\section{Cureus}

\section{Item}

1 Selects appropriate needle driver and sutures

$2 \quad$ Needle loaded from $1 / 2$ to $2 / 3$ from tip

3 Uses laparoscopic needle holder and forceps to handle needle

$4 \quad$ Needle enters tissues at right angles ( $80 \%$ of bites)

5 Single attempt at needle passage through tissues ( $90 \%$ of bites)

6 Follow through on curve of needle on entrance ( $80 \%$ of bites)

7 Follow through on curve of needle on exit ( $80 \%$ of bites)

8 Minimal damage with forceps

$9 \quad$ Equal suture spacing

10 Equal bites on each side ( $80 \%$ of bites)

11 Square knots (minimum three throws on knots)

12 Suture cut to appropriate length (does not interfere with next stitch)

13 Apposition of tissues without excessive tension on suture

14 Appropriate alignment of tissues (no torsion)

Maximum total score, Total score

\section{Not Done or Incorrect Done Correctly}

0

1

1

1

1

1

1

1

1

1

1

1

1

1

\section{TABLE 3: Task-Specific Checklist}

Adapted from Reznick, et al.

\section{Module 4: Cholecystectomy}

The residents' learning objectives here are to develop specific skills for performing a cholecystectomy on an animal model. This is accomplished by placing a porcine liver and a gall bladder (obtained from an abattoir) inside the box trainer (Figure 5). While positioned upside down, the extra liver is removed to ensure that the gall bladder, bile duct, and vessels are intact (this should be approximately $15-20 \mathrm{~cm} \times 25-30 \mathrm{~cm}$ ). The specimen is fixed to a cautery pad and positioned on a piece of Styrofoam ${ }^{\mathrm{TM}}$ (Dow Chemical Co., Midland, MI, USA) while the margins of the liver are stapled to the Styrofoam ${ }^{\mathrm{TM}}$ in order to prevent it from being lifted up during instrumental manipulation. Finally, the secured specimen is placed on a shallow tray and the tray is positioned within the box trainer. 


\section{Cureus}

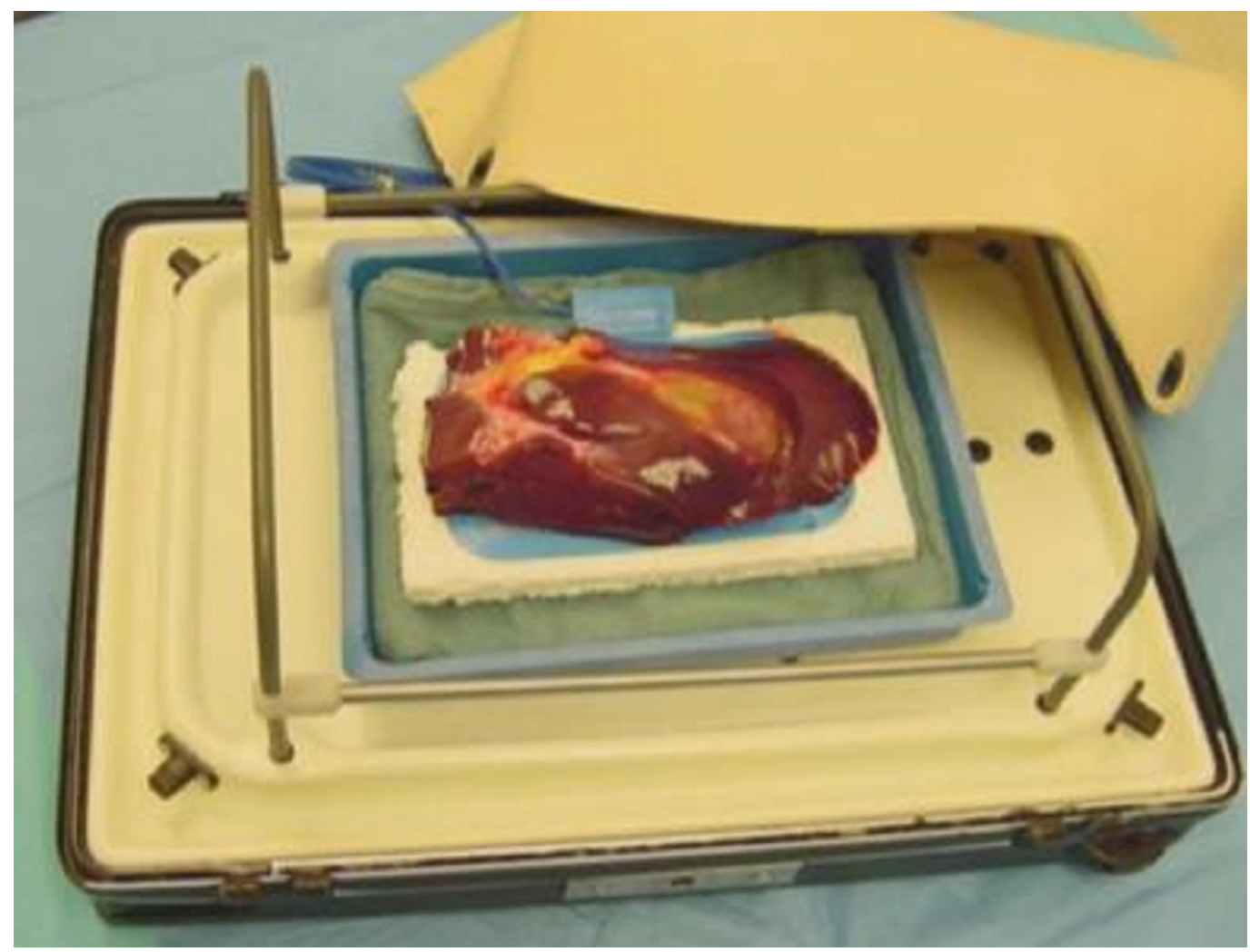

FIGURE 5: Cholecystectomy lap trainer.

An experienced trainer supervises these sessions and can provide feedback based on the GRS (Table 2) and skill-specific checklist (Table 4) adapted from Vassiliou, et al. [17]. 


\section{Cureus}

\section{Item}

1 Selects appropriate needle driver and sutures

2 Needle loaded from $1 / 2$ to $2 / 3$ from tip

3 Uses cautery only when all conducting areas are in field of view

4 Has good control of the instrument, minimizes recoil

$5 \quad$ Grasps gallbladder near clips to begin dissection

6 Readjusts tension on gallbladder to optimize exposure

$7 \quad$ Avoids dissecting into liver, causing undue bleeding

8 Avoids perforation of the gallbladder

$9 \quad$ Avoids spillage of gallstones

10 Maximizes useful dissection in one area before changing approach

11 Performs dissection in the appropriate plane the majority of the time

12 Obviates the need for surgeon takeover

Maximum total score, Total score

\section{Not Done or Incorrect Done Correctly}

0

1

0

1

1

1

1

1

1

1

1

1

1

1

TABLE 4: Task-Specific Checklist: Dissection of the Gallbladder from the Liver Bed Adapted from Vassiliou, et al.

\section{Module 5: Pyloroplasty}

The residents' learning objectives here are to develop the necessary specific skills to perform a pyloroplasty on an inanimate model. A stomach is made with sponge and colored appropriately. An inflated condom is introduced into the stomach to increase its volume. The stomach is then placed in the box trainer (Figure 6). 


\section{Cureus}

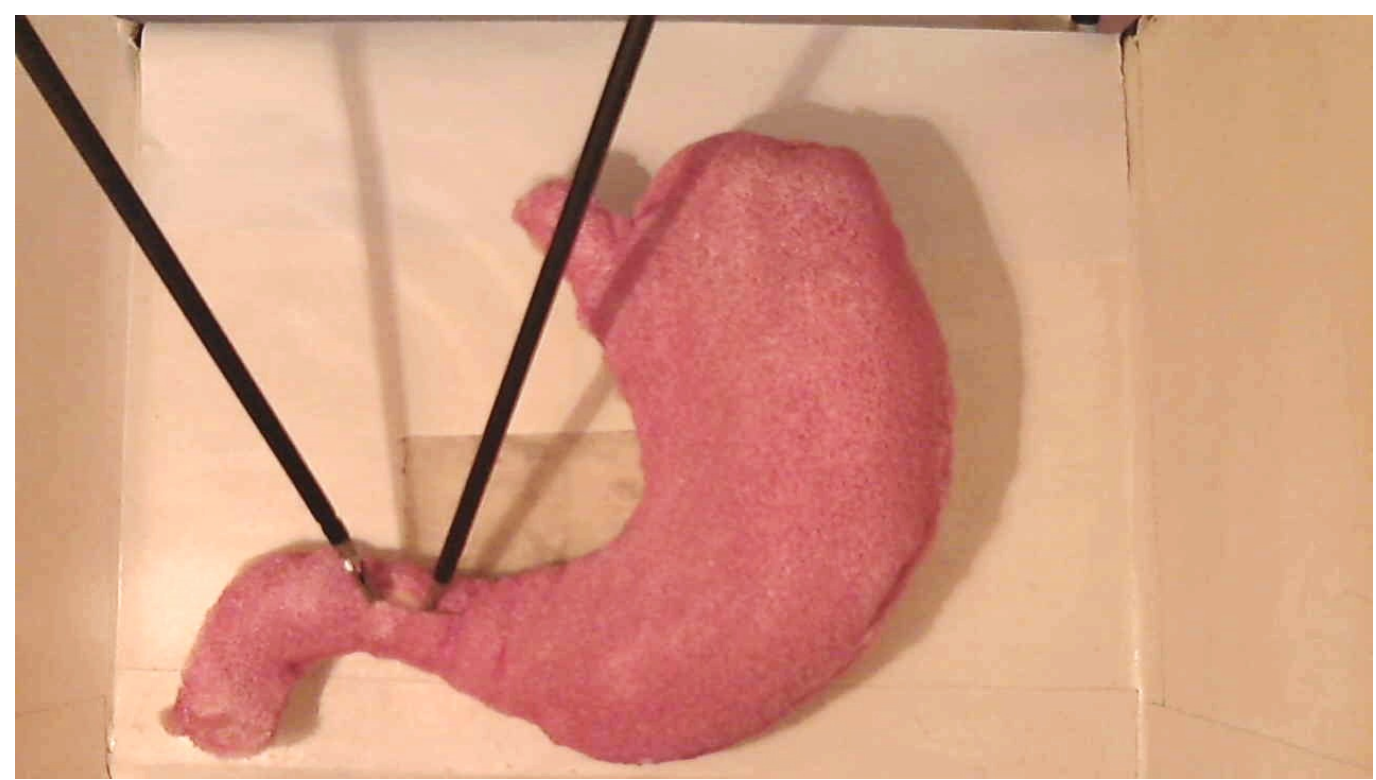

FIGURE 6: Pyloroplasty lap trainer.

An experienced trainer supervises the practice sessions at this module and can provide feedback based on the GRS (Table 2) and skill-specific checklist (Table 5). 


\section{Cureus}

\section{Item}

$1 \quad$ Palpates extent of pylorus

2 Perpendicular (non-scythed) entry into stomach

3 Atraumatic entry to stomach

4 Adequate length to encompass pylorus (minimum $3 \mathrm{~cm}$ )

$5 \quad$ Stay sutures held with snaps

6 Selects appropriate needle driver and suture

$7 \quad$ Needle loaded $1 / 2$ to $2 / 3$ from tip

8 Index used to stabilize needle driver

$9 \quad$ Needle enters bowel at right angles ( $80 \%$ of bites)

17 Equal bites on each side on $80 \%$ of bites

18 Square knots

19 Minimum three throws on knots

20 Suture cut to appropriate length (does not interfere with next stitch)

$21 \quad$ No mucosal pouting

\section{Not Done or Incorrect Done Correctly}

0

1

1

1

1

1

1

1

1

1

1

1

1

1

1

1

1

1

1

1

1

1

1

1

(23)

\section{TABLE 5: Task-Specific Checklist: Pyloroplasty}

\section{Module 6: Ectopic pregnancy}

The residents' learning objectives here are to develop specific skills related to ectopic pregnancy. Modeling clay, such as Play-Doh ${ }^{\circledR}$ (Hasbro, Pawtucket, RI, USA), is used to shape 


\section{Cureus}

the uterus (Figure 7). A longitudinal trench is left on top of the fundus, where the fallopian tubes are placed and secured. A segment of pig bowel is cut longitudinally and trimmed to a desirable size, approximately 2 or $3 \mathrm{~cm}$ wide. One or more chickpeas, each representing an ectopic pregnancy, are positioned at its center. More than one pea can be placed in the model to allow for repeated practice. The top portion of the bowel is folded in order to cover the chickpea(s) and the opposite walls of the bowel strip are sutured together using a running stitch (with 2-0 silk on a straight needle). The end of the tube that is thereby created is placed in the trench on the body of the plasticine uterus. The model is then placed on a grounding cautery pad inside a plastic container that is lined with a towel. This model is then placed in the box trainer.

This module is for more advanced learners. Using this simple model, the residents learn laparoscopic management of an ectopic pregnancy. Appropriate task-related GRS (Table 2) and checklists (Table 6) are used for both formative and summative feedback. The checklist is adapted from Larsen, et al. [18].

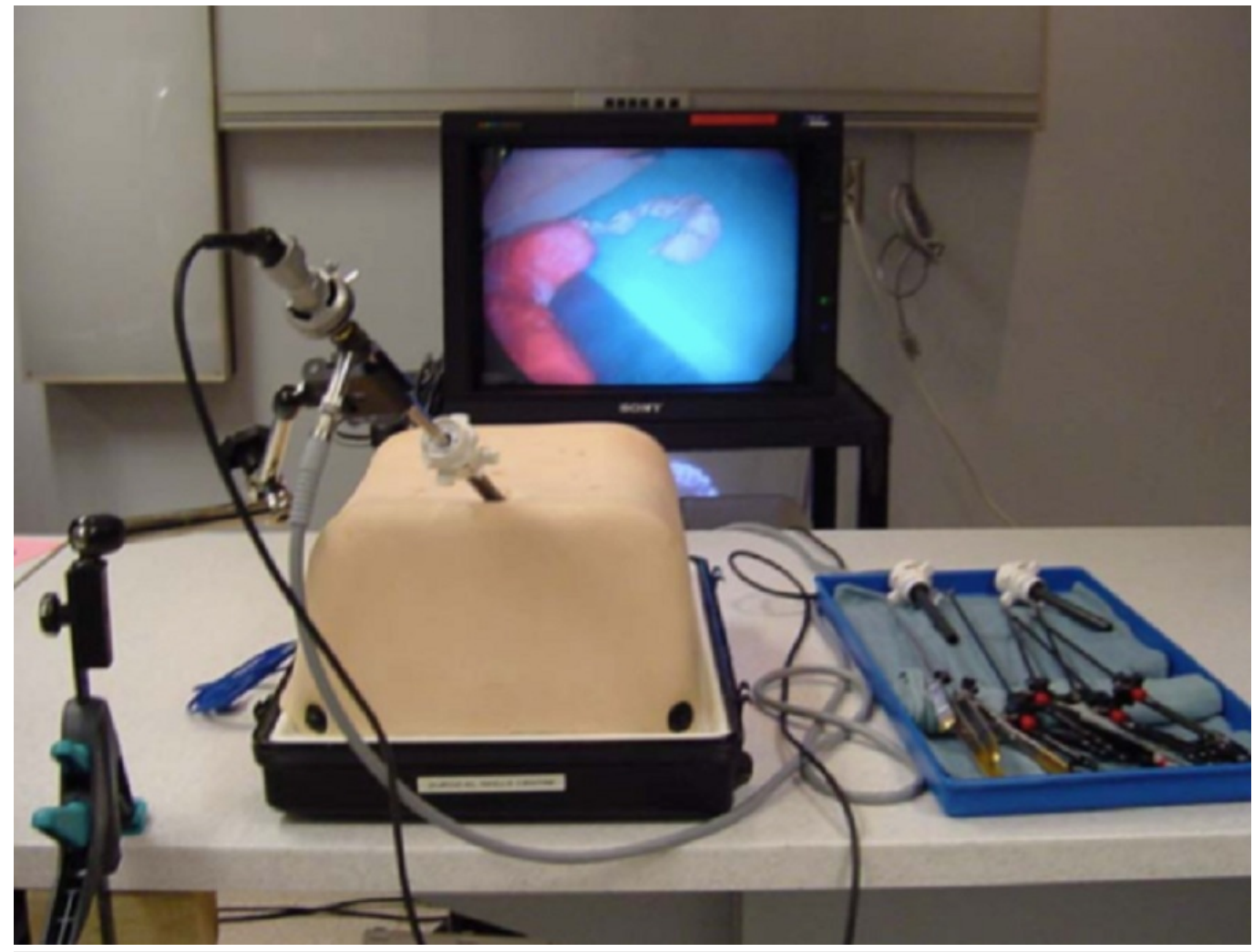

FIGURE 7: Ectopic pregnancy lap trainer. 


\section{Cureus}

\begin{tabular}{|c|c|c|c|}
\hline Item & & $\begin{array}{l}\text { Not Done } \\
\text { or } \\
\text { Incorrect }\end{array}$ & $\begin{array}{l}\text { Done } \\
\text { Correctly }\end{array}$ \\
\hline 1 & $\begin{array}{l}\text { Selects appropriate instruments (graspers, bipolar diathermy, scissors, rinse/suction, } \\
\text { bag) }\end{array}$ & 0 & 1 \\
\hline 2 & Starts the video recording & 0 & 1 \\
\hline 3 & Inserts instruments, grasper in lateral trocar, other instruments in medial trocar & 0 & 1 \\
\hline 4 & Identifies the anatomy & 0 & 1 \\
\hline 5 & Operates from centre towards lateral & 0 & 1 \\
\hline 6 & Uses grasper in right hand and grasps the Fallopian tube & 0 & 1 \\
\hline 7 & Uses bipolar grasper in left hand and uses diathermy on salpinx and mesosalpinx & 0 & 1 \\
\hline 8 & Starts close to tubal corner of uterus & 0 & 1 \\
\hline 9 & $\begin{array}{l}\text { Shifts bipolar grasper to scissors in left trocar and cuts the coagulated tissue close to the } \\
\text { Fallopian tube }\end{array}$ & 0 & 1 \\
\hline 10 & $\begin{array}{l}\text { Continues alternated use of bipolar grasper and scissors to remove Fallopian tube. } \\
\text { Uses instruments in the trocars providing the most appropriate access to the tissue }\end{array}$ & 0 & 1 \\
\hline 11 & $\begin{array}{l}\text { Takes care not to use diathermy on the ovary and the supplying artery and other non- } \\
\text { target tissue }\end{array}$ & 0 & 1 \\
\hline 12 & $\begin{array}{l}\text { Uses bag or grasper to remove the dissected tissue and rinse/suction device to clean up } \\
\text { blood }\end{array}$ & 0 & 1 \\
\hline 13 & Uses bipolar grasper to coagulate any remaining bleeding vessels/tissue & 0 & 1 \\
\hline 14 & Stops video recording & 0 & 1 \\
\hline \multicolumn{2}{|c|}{ Maximum total score, Total score } & & (14) \\
\hline
\end{tabular}

\section{TABLE 6: Task-Specific Checklist: Laparoscopic Salpingectomy}

Adapted from Larsen, et al.

\section{Module 7: Ovarian cystectomy}

The residents' learning objectives here are to develop specific skills related to ovarian cystectomy. To make the ovarian model, a balloon filled with honey was placed inside a larger balloon inflated with air to form a sphere approximately $4 \mathrm{~cm}$ in diameter. The two balloons were tied off separately. The model was attached to the box trainer with a crocodile clamp - suction cup assembly. Finally, the model was covered with a synthetic skin (Figure 8). 


\section{Cureus}

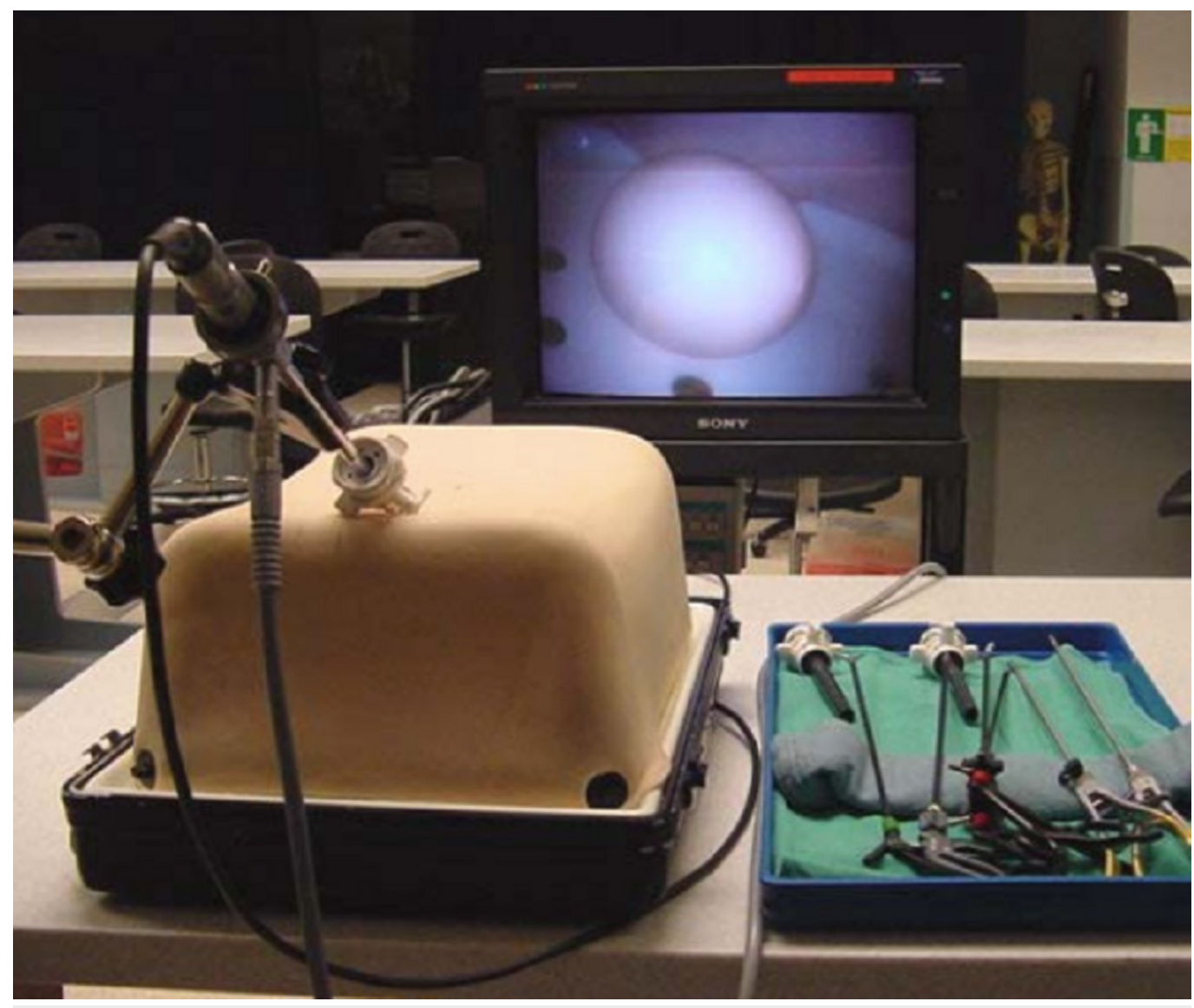

FIGURE 8: Ovarian cystectomy lap trainer.

This module is again for advanced learners. Using this model, the residents learn laparoscopic management of cholecystectomy. Appropriate task-related GRS (Table 2) and checklists (Table 7) are used for feedback. 


\section{Cureus}

\begin{tabular}{|c|c|c|c|}
\hline Item & & $\begin{array}{l}\text { Not Done or } \\
\text { Incorrect }\end{array}$ & $\begin{array}{l}\text { Done } \\
\text { Correctly }\end{array}$ \\
\hline 1 & Inspects the pelvis and upper abdomen & 0 & 1 \\
\hline 2 & Selects atraumatic graspers & 0 & 1 \\
\hline 3 & Stabilizes ovary & 0 & 1 \\
\hline 4 & Selects laparoscopic scissors & 0 & 1 \\
\hline 5 & Introduces scissors under direct visualization & 0 & 1 \\
\hline 6 & Incises the ovarian cortex over the ovarian cyst & 0 & 1 \\
\hline 7 & Does not puncture the cyst & 0 & 1 \\
\hline 8 & Bluntly dissects the cyst wall free from the overlying ovarian cortex & 0 & 1 \\
\hline 9 & $\begin{array}{l}\text { Using graspers, provides traction and counter-traction until the entire cyst } \\
\text { wall is free }\end{array}$ & 0 & 1 \\
\hline 10 & Always keeps instruments in view while in the abdomen & 0 & 1 \\
\hline 11 & Does not overshoot the target more than $20 \%$ of the time & 0 & 1 \\
\hline 12 & Irrigates the area & 0 & 1 \\
\hline 13 & Inspects for hemostasis & 0 & 1 \\
\hline 14 & Follows removal of cyst from the abdomen with the camera & 0 & 1 \\
\hline \multicolumn{2}{|c|}{ Maximum total score, Total score } & & (14) \\
\hline
\end{tabular}

\section{TABLE 7: Task-Specific Checklist: Laparoscopic Ovarian Cystectomy}

\section{Discussion}

The advantages of laparoscopic surgery over open surgery are the same in Haiti as they are in Canada. Laparoscopic surgery avoids large open wounds and incisions, thereby reducing postoperative discomfort and the need for analgesia. Fine laparoscopic instruments cause little tissue damage and blood loss. Moreover, the rate of postoperative complications is generally lower, especially those related to the wound (e.g. infection, dehiscence, herniation, etc.). The procedure is performed within the body cavity, which reduces most of the handling associated with open procedures. This reduces postoperative adhesions, infections, and keloids. Cumulatively, these benefits help to decrease the recovery period and associated hospital stay [19].

For these reasons, laparoscopic surgery is desirable in developing countries like Haiti. However, both limited access to training and financial restraints impede learning and disseminating the procedure. We describe a locally developed box trainer and accompanying educational curriculum that can help to implement a sustainable laparoscopic skills training program. This may ultimately prepare JUH surgical and obstetrical residents to train and work at other 
hospitals throughout Haiti where laparoscopy is already being performed. Both the trainer and its curriculum should be piloted and evaluated in order to assess its clinical feasibility.

\section{Conclusions}

Laparoscopic surgery offers numerous advantages. However, in developing countries, there are logistical and financial barriers to its use. The purpose of this technical report was to provide surgical educators with a cost-efficient and locally developed simulation teaching tool. Comprised of seven locally developed modules and validated assessment tools, it may help mitigate barriers to laparoscopic training and eventually help facilitate its use in developing countries. A future pilot and assessment of both the tool and its accompanying curriculum may help to establish its clinical utility.

\section{Additional Information}

\section{Disclosures}

Human subjects: All authors have confirmed that this study did not involve human participants or tissue. Animal subjects: All authors have confirmed that this study did not involve animal subjects or tissue. Conflicts of interest: In compliance with the ICMJE uniform disclosure form, all authors declare the following: Payment/services info: All authors have declared that no financial support was received from any organization for the submitted work. Financial relationships: All authors have declared that they have no financial relationships at present or within the previous three years with any organizations that might have an interest in the submitted work. Other relationships: All authors have declared that there are no other relationships or activities that could appear to have influenced the submitted work.

\section{Acknowledgements}

The Tuckamore Simulation Research Network and the Emergency Medicine Educational Committee, Memorial University of Newfoundland, supported this project. We would also like to thank Lisa Satterthwaite (RPN, ORT), Senior Manager, University of Toronto Surgical Skills Centre and SimSinai Centre At Mount Sinai Hospital for sharing assessment checklists.

\section{References}

1. Choy I, Kitto S, Adu-Aryee N, Okrainec A: Barriers to the uptake of laparoscopic surgery in a lower-middle-income country. Surg Endosc. 2013, 27:4009-15. 10.1007/s00464-013-3019-z

2. Asbun HJ, Berguer R, Altamirano R, Castellanos H: Successfully establishing laparoscopic surgery programs in developing countries. Clinical results and lessons learned. Surg Endosc. 1996, 10:1000-1003. 10.1007/s004649900223

3. Guo Y, Henao O, Jackson T, Quereshy F, Okrainec A: Commercial videoconferencing for use in telementoring laparoscopic surgery. Medicine Meets Virtual Reality 21. Westwood JD, Westwood SW, Felländer-Tsai L, Fidopiastis CM, Haluck RS, Robb RA, Senger S, Vosburgh KG (ed): IOS Press, Amsterdam, The Netherlands; 2014. 196:147-49. 10.3233/978-1-61499-3759-147

4. Okrainec A, Vassiliou M, Kapoor A, Pitzul K, Henao O, Kaneva P, Jackson T, Ritter EM: Feasibility of remote administration of the Fundamentals of Laparoscopic Surgery (FLS) skills test. Surg Endosc. 2013, 27:4033-37. 10.1007/s00464-013-3048-7

5. Henao Ó, Escallón J, Green J, Farcas M, Sierra JM, Sánchez W, Okrainec A: Fundamentals of laparoscopic surgery in Colombia using telesimulation: an effective educational tool for distance learning (Article in Spanish). Biomedica. 2013, 33:107-14.

6. Choy I, Fecso A, Kwong J, Jackson T, Okrainec A: Remote evaluation of laparoscopic performance using the global operative assessment of laparoscopic skills. Surg Endosc. 2013, 27:378-83. 10.1007/s00464-012-2456-4

7. Mikrogianakis A, Kam A, Silver S, Bakanisi B, Henao O, Okrainec A, Azzie G: Telesimulation: 
an innovative and effective tool for teaching novel intraosseous insertion techniques in developing countries. Acad Emerg Med. 2011, 18:420-27. 10.1111/j.1553-2712.2011.01038.x

8. Okrainec A, Smith L, Azzie G: Surgical simulation in Africa: the feasibility and impact of a 3day fundamentals of laparoscopic surgery course. Surg Endosc. 2009, 23:2493-98. 10.1007/s00464-009-0424-4

9. Cristancho SM, Moussa F, Dubrowski A: A framework-based approach to designing simulation-augmented surgical education and training programs. Am J Surg. 2011, 202:34451.10.1016/j.amjsurg.2011.02.011

10. Cristancho S, Moussa F, Monclou A, Moncayo C, Rueda C, Dubrowski A: Progressive simulation-based program for training cardiac surgery-related skills. Medicine Meets Virtual Reality 18: NextMed. Westwood JD, Westwood SW, Felländer-Tsai L, Haluck RS, Haluck RS, Robb RA, Senger S, Vosburgh KG (ed): IOS Press, Amsterdam, The Netherlands; 2011. 163:150-55. 10.3233/978-1-60750-706-2-150

11. Reznick R, Regehr G, MacRae H, Martin J, McCulloch W: Testing technical skill via an innovative "bench station" examination. Am J Surg. 1997, 173:226-30. 10.1016/S00029610(97)89597-9

12. Pellen M, Horgan L, Roger Barton J, Attwood S: Laparoscopic surgical skills assessment: can simulators replace experts?. World J Surg. 2009, 33:440-47. 10.1007/s00268-008-9866-4

13. Steigerwald SN, Park J, Hardy KM, Gillman L, Vergis AS: Establishing the concurrent validity of general and technique-specific skills assessments in surgical education. Am J Surg. 2016, 211:268-73. 10.1016/j.amjsurg.2015.04.024

14. Lund L, Dubrowski A, Carnahan H: A modular approach for training urologists in laparoscopy . BJU Int. 2007, 100:1216-18. 10.1111/j.1464-410X.2007.07253.x

15. Dubrowski A, Park J, Moulton CA, Larmer J, MacRae H: A comparison of single- and multiplestage approaches to teaching laparoscopic suturing. Am J Surg. 2007, 193:269-73. 10.1016/j.amjsurg.2006.07.013

16. Sabbagh R, Chatterjee S, Chawla A, Kapoor A, Matsumoto ED: Task-specific bench model training versus basic laparoscopic skills training for laparoscopic radical prostatectomy: a randomized controlled study. Can Urol Assoc J. 2009, 3:22-30.

17. Vassiliou MC, Feldman LS, Andrew CG, Bergman S, Leffondré K, Stanbridge D, Fried GM: A global assessment tool for evaluation of intraoperative laparoscopic skills. Am J Surg. 2005, 190:107-13. 10.1016/j.amjsurg.2005.04.004

18. Larsen CR, Grantcharov T, Schouenborg L, Ottosen C, Soerensen JL, Ottesen B: Objective assessment of surgical competence in gynaecological laparoscopy: development and validation of a procedure-specific rating scale. BJOG. 2008, 115:908-16. 10.1111/j.14710528.2008.01732.x

19. Agha R, Muir G: Does laparoscopic surgery spell the end of the open surgeon? . J R Soc Med. 2003, 96:544-46. 